\title{
Carotid Artery-Cavernous Segment Injury during an Endoscopic Endonasal Surgery: A Case Report and Literature Review of the Overlooked Option for Surgical Trapping in the Hyperacute Phase
}

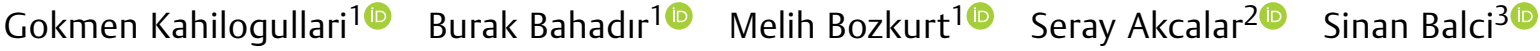 \\ Anil Arat ${ }^{3}$ (1)
}

${ }^{1}$ Department of Neurosurgery, Ankara University, Ankara, Turkey

2 Department of Radiology, Ankara University, Ankara, Turkey

${ }^{3}$ Department of Radiology, Hacettepe University, Ankara, Turkey
Address for correspondence Gokmen Kahilogullari, MD, PhD, Department of Neurosurgery, Ankara University, Sihhiye, Ankara, Turkey (e-mail: gokmenkahil@hotmail.com).

J Neurol Surg Rep 2021;82:e53-e62.

\begin{abstract}
Keywords

- endonasal endoscopic surgery

- endovascular treatment

- ICA-cavernous segment

- pituitary adenoma

- trapping

- urgent transcranial surgery

Internal carotid artery (ICA) injury is a catastrophic complication of endoscopic endonasal surgery (EES). However, its standard management, emergent endovascular treatment, may not always be available, and the transnasal approach may be insufficient to achieve hemostasis.

A 44-year-old woman with pituitary adenoma underwent EES complicated with the ICA cavernous segment injury (CSI). In urgent intraoperative angiogram, a good collateral flow from the contralateral carotid circulation was observed. Due to the unavailability of intraoperative embolization, emergent surgical trapping was performed by combined transcranial and cervical approach. The patient recovered but later developed a giant cavernous pseudoaneurysm. During the pseudoaneurysm embolization, ICA was directly accessed via a 1.7-F puncture hole using a bare microcatheter technique. Then, both the aneurysm and parent artery were obliterated with coils. At the 4-year followup, the patient was asymptomatic without a residual tumor. To our knowledge, this is the first case of ICA-CSI during EES successfully treated with ICA trapping as a lifesaving urgent surgery that achieved a complete recovery after a pseudoaneurysm embolization. Although several studies reported that EES-related ICA-CSIs with percutaneous carotid artery access, neither our surgical salvage technique nor our carotid access and tract embolization techniques were previously described.
\end{abstract}

\section{Introduction}

Recently, endoscopic endonasal surgery (EES) has been increasingly performed for skull base and sellar pathologies in patients of all ages, albeit its complications. ${ }^{1-10}$ Despite the numerous reports on EES, there is a paucity of reports on its complications, especially those involving the internal carotid received

May 14, 2021

accepted

September 20, 2021
DOI https://doi.org/

$10.1055 / \mathrm{s}-0041-1740511$. ISSN 2193-6358.

\footnotetext{
(C) 2021. The Author(s).

This is an open access article published by Thieme under the terms of the Creative Commons Attribution-NonDerivative-NonCommercial-License, permitting copying and reproduction so long as the original work is given appropriate credit. Contents may not be used for commercial purposes, or adapted, remixed, transformed or built upon. (https://creativecommons.org/ licenses/by-nc-nd/4.0/) Georg Thieme Verlag KG, Rüdigerstraße 14, 70469 Stuttgart, Germany
} 
artery (ICA) injury, commonly at its cavernous part. ${ }^{11-25}$ In this report, we present the first case treated with surgical trapping, an emergent surgical treatment, for EES-related carotid injury, and review 15 studies describing 33 cases of EES-related ICAcavernous segment injury with special attention to treatment options. Our patient finally recovered well after the initial lifesaving surgical treatment followed by the unique endovascular approach for the residual carotid pseudoaneurysm in the subacute phase. Although direct endovascular treatment remains the best option for this catastrophic injury, alternative methods should also be known.

\section{Case Report}

A 44-year-old female patient presented to our institution with hand and foot enlargement. On admission, no motor or sensory deficits were observed; however, bilateral temporal visual field cuts were detected. Laboratory workup revealed elevated somatomedin-C (IGF-1), 413 (94-269) ng/mL; somatotropin (GH), $3.86(0-3.5) \mathrm{ng} / \mathrm{mL}$; adrenocorticotropic hormone, 84.06 (7.2-63.3) pg/mL; and cortisol levels, 29.06 (6.7-42.6) $\mu$. On magnetic resonance imaging, a macroade-

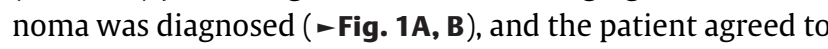
undergo an endonasal surgical treatment. Intraoperatively, the patient was placed in the standard supine position, with her head in a horseshoe cap and minimal extension. After reaching the sellar region, the bone was breached to reach the dura. As soon as the dura was reached using a number 15 blade, severe bleeding occurred. First, cotton, Surgicel (Ethicon) and bipolar cauterization and eventually muscle and fat tamponade were used but were unsuccessful to control the bleeding. Afterward, an emergent neck dissection was performed to place a temporary clip in the carotid artery. Then, as the bleeding was temporarily controlled, an intraoperative angiogram was performed, which revealed a lacerated cavernous ICA segment (-Fig. 2A). A good collateral flow from the contralateral carotid circulation was also observed (-Fig. 2B). Due to the unavailability of emergent neurointerventional support at that time, a decision was made to proceed with craniotomy emergently to prevent impending exsanguination and urgent transcranial surgery was performed. The patient was placed in supine position and the

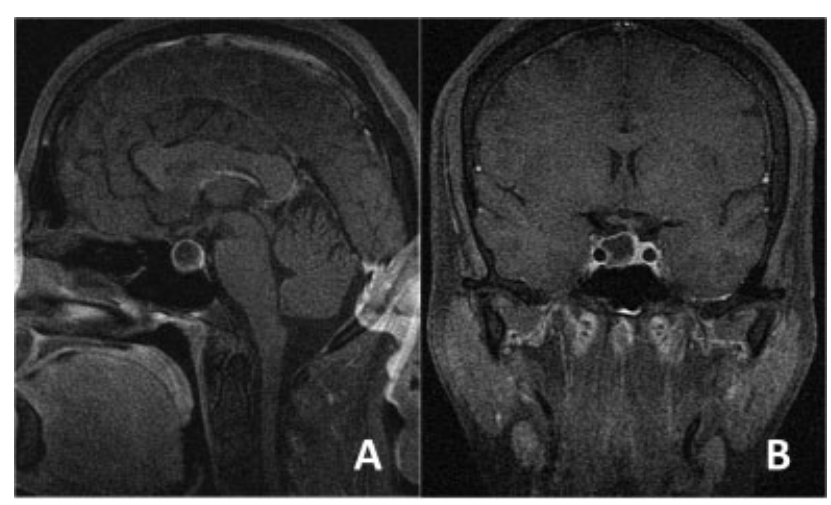

Fig. 1 Preoperative gadolinium-enhanced magnetic resonance imaging of the patient in sagittal (A) and coronal (B) sections demonstrating the pituitary adenoma.

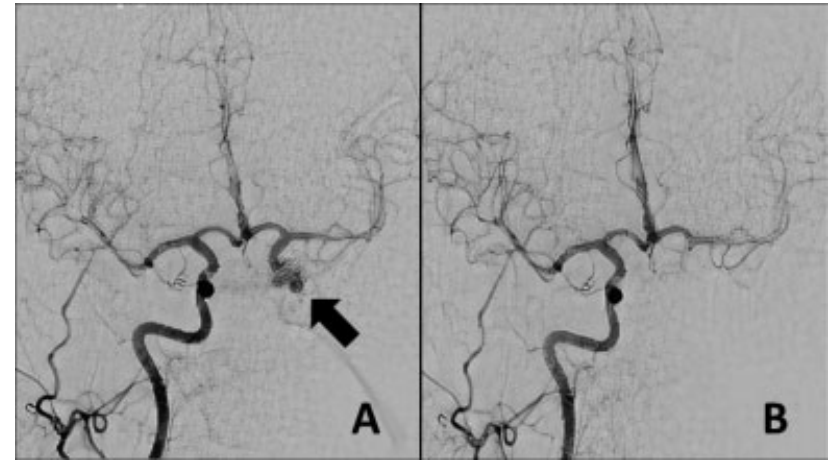

Fig. 2 Intraoperative emergent angiography showed left internal carotid artery (ICA)-cavernous segment injury (arrow) (A) and good collateral flow from the right ICA circulation (B).

head was rotated at 30 degrees counterclockwise. A minipterional craniotomy was performed, and the anterior clinoid process was removed using a high-speed drill and rongeur extradurally. The dura was opened after removing the anterior clinoid process. On close inspection, no trace of subarachnoid hemorrhage and a normal appearing brain were observed. A proximal sylvian dissection was performed. All the supraclinoid portions of the ICA including the anterior choroidal, posterior communicating, and ophthalmic arteries were exposed. The ICA was trapped between its cervical and transitional segments (just proximal to the origin of the ophthalmic artery) by placing permanent aneurysm clips. Immediately after trapping, hemostasis was also verified endoscopically. Intraoperative Doppler sonography was used to determine the flow distal to the dural ring. After ensuring the distal flow, the tumor was completely removed via a transsylvian route. The patient again underwent an immediate postoperative angiography that confirmed the absence of bleeding and maintenance of good collateral supply to the ipsilateral carotid circulation above the cavernous segment. After a close observation in the neurointensive care unit postoperatively, the patient was transferred to the neurosurgical ward on postoperative day 3 with a Glasgow Coma Score of 15 and an intact neurological examination, except for left ptosis. On follow-up, the patient's serum hormone levels were normalized, and the ptosis had significantly improved at 6 months. The patient was readmitted to another institution for follow-up angiography at 11 months postoperatively. A cerebral angiogram demonstrated reconstitution of ICA flow inferiorly via the left vertebral and external carotid arteries (-Supplementary file 1). Below the carotid bifurcation, the common carotid artery was completely occluded. Superiorly, a persistent flow in the internal carotid circulation was observed via a significantly stenosed parent artery at the level of the previously placed clip. In the interim, an $\sim 40$-mm cavernous pseudoaneurysm had developed. After consultation with the previous operator, endovascular approach was planned for the pseudoaneurysm. However, there was no antegrade access to the pseudoaneurysm from the aortic arch due to the previous carotid sacrifice (-Supplementary file 1). Under general anesthesia, the left vertebral artery 
was first catheterized through a transfemoral route. Vertebral angiograms demonstrated reconstruction of the left internal carotid circulation via the external carotid and distally to the posterior communicating arteries and antegrade filling of giant pseudoaneurysm and the ICA (-Supplementary file 1). Since the ICA had been surgically occluded, direct carotid puncture at the cervical segment of the ICA was performed using a 21-G micropuncture needle (Merit Medical Systems, United States) under fluoroscopic guidance (-Supplementary file 1). A Transcend 14 microwire (Stryker Neurovascular, United States) was placed through the needle, and then the needle was directly exchanged with an SL-10 microcatheter (Stryker Neurovascular, United States) over the Transcend microwire without using a vascular sheath (-Supplementary file 1 ). The supraclinoid portion of the left ICA was directly catheterized with the same microcatheter over a Synchro 14 microwire (Stryker Neurovascular, United States). The giant aneurysm and its neighboring parent artery were occluded with detachable bare platinum coils followed by an N-butyl cyanoacrylate injection. At the end of the procedure, both aneurysm and neighboring left ICA segment occlusion were demonstrated and left intracranial carotid circulation reconstruction was verified on the left vertebral and right carotid angiograms (-Supplementary file 1). While withdrawing the microcatheter, a glue bubble was first formed at the tip of the microcatheter by very slowly injecting an embolizing agent, and then the glue bubble was gently retracted with the microcatheter down the puncture site to plug the puncture hole from the endoluminal site. Subsequently, the glue was injected into the puncture tract while further withdrawing the microcatheter (-Supplementary file 1). Manual compression was not applied, and no neck hematoma was observed at the puncture site. The patient awakened from anesthesia uneventfully. Further follow-up showed persistent pseudoaneurysm and parent artery occlusion. The patient was asymptomatic including her previously affected third nerve function, and she had a normal hormonal profile at the 4-year follow-up.

\section{Discussion}

EES has become a routine approach for lesions extending from the frontal sinus to the second cervical vertebra in the sagittal plane and from the roof of the orbit and floor of the middle cranial fossa to the jugular foramen in the coronal plane in skull base surgery. ${ }^{26,27}$ The main advantages of EES are absence of skin incisions (cosmetically more acceptable), minimally invasive nature, diminished postoperative pain, and short duration of postoperative hospital stay, which promoted its popularity. ${ }^{26}$ In spite of these advantages, certain complications may occur, including but not limited to hemorrhagic vascular complications, rhinorrhea, and infection. ${ }^{2,28,29}$ Among these, ICA injury is a life-threatening complication of EES. $5,17,29-31$

The incidence of ICA injury during neurosurgical transsphenoidal interventions is 0.2 to $1.4 \%$ for pituitary surgery. ${ }^{17,31}$ ICA injury during EES is rare and less common as compared with microsurgical series. ${ }^{17,32-35}$ On the other hand, some studies have revealed contrasting opinions. ${ }^{36}$ Obviously, the rule of thumb is to prevent these injuries by proper training and operator experience, using the " 2 surgeons, 4 hands" method, and having a good grasp of patientspecific anatomy utilizing the best preoperative imaging techniques. $^{30,37-43}$ Anatomical considerations in EES must be kept in the mind to avoid this serious complication. ${ }^{44-46}$ However, ICA injury may still occur in the best of hands, ${ }^{47}$ and apart from exsanguination, this injury may lead to a diverse range of vascular findings such as pseudoaneurysms, arterial spasm, arterial thrombosis/emboli, and caroticocavernous fistula formation. ${ }^{3,4}$ Although endovascular treatment is currently the best choice for the management of ICA injury during EES, surgical options must be considered in cases of unavailable or delayed emergent endovascular treatment. $8,9,25,48-51$ Therefore, this report aimed to describe the alternative surgical approach in such case scenario by demonstrating our case and a literature review. Surprisingly, we discovered that this process with subsequent ICA trapping in the hyperacute phase has not yet been reported in the literature, although reverting to craniotomy in such a catastrophic emergency is basically an intuitive procedure.

Several literature reports showed data on ICA-cavernous segment injury during EES operations, as summarized in -Table 1. ${ }^{11-25}$ In a larger series, Romero et al described four arterial injuries out of their 800 EES cases. ${ }^{23}$ However, only one of these injuries occurred in the cavernous ICA. In this case, an emergent angiogram showed sufficient collaterals via the circle of Willis; therefore, the operators were able to proceed with the endovascular occlusion of ICA, and 4 months later, they removed the tumor via orbitofrontal craniotomy. Additionally, in same study, the authors reviewed the literature and described that 25 out of 7,336 patients undergoing EES had arterial injury intraoperatively (0.34\%). They found 19 ICA injuries in the same (0.26\%) metaanalysis. In the largest series of EES describing ICA injury, Kalinin et al described four cases of ICA-cavernosal segment injury in their 3,000 patients from Burdenko (0.13\%). ${ }^{19}$ Among them, one had ICA occlusion and three had pseudoaneurysm formation; three of them underwent endovascular treatment. One patient required bilateral decompressive craniotomy postoperatively and subsequently died. In a systematic review on ICA injury in EES, Chin et al evaluated 25 papers revealing 50 patients with injury ${ }^{52}: 34$ at the ICAcavernous segment and 3 at the ophthalmic artery, occurring more commonly on the left eye (1.3/1). In 35 patients who achieved initial hemostasis through packing, four underwent an endoscopic clip sacrifice, three had bipolar coagulation to seal the defect, and one had bipolar coagulation to sacrifice the ICA. Intraoperative or immediate postoperative angiography was reported in 27 cases in this meta-analysis. Our literature review, as summarized in -Table 1, yielded 33 patients (12 males and 15 females; no gender information was available for 6 patients) with a mean age of 47.36 years (range: $12-82$ years). The most common pathology was pituitary tumor (18 patients: 4 patients with acromegaly, 4 with nonfunctional tumors, 2 with Cushing syndrome, 2 
Cavernous Segment Injury during Endonasal Surgery Kahilogullari et al.

Table 1 Previous literature data on patients with ICA-cavernous segment injury during EES

\begin{tabular}{|c|c|c|c|c|c|c|c|c|c|c|}
\hline$P$ & $S / \operatorname{Re}$ & $\mathrm{A} / \mathrm{G}$ & Pathology & Injury & Side & Initial & IA & Finding & ICA status/Repair & $\begin{array}{l}\text { Patient } \\
\text { status }\end{array}$ \\
\hline 1 & $\begin{array}{l}1 \\
(11,12)\end{array}$ & $22 / F$ & PT-Acro & TD & $\mathrm{R}$ & $\mathrm{Pac}$ & + & PA & $\mathrm{EC}$ & NS \\
\hline 2 & $\begin{array}{l}2 \\
(13)\end{array}$ & $42 / M$ & Car & TD & $\mathrm{L}$ & Pac & + & PA & EBO & Li/NA \\
\hline 3 & $\begin{array}{l}3 \\
(14) \\
\end{array}$ & $31 / \mathrm{M}$ & PT-Acro & un & $\mathrm{L}$ & $\mathrm{Pac}$ & + & un & $\mathrm{EC}$ & NS \\
\hline 4 & $\begin{array}{l}4 \\
(15)\end{array}$ & $45 / M$ & PT-NP & $\mathrm{DI}$ & $R$ & $\mathrm{Pac}+\mathrm{MP}$ & + & un & $\mathrm{ESt}+\mathrm{EC}$ & NS \\
\hline 5 & $\begin{array}{l}4 \\
(15)\end{array}$ & $12 / \mathrm{M}$ & PT-Cushing & DRB & un & $\mathrm{Pac}$ & + & un & $\mathrm{ESt}+\mathrm{EC}$ & NS \\
\hline 6 & $\begin{array}{l}5 \\
(16)\end{array}$ & $41 / \mathrm{F}$ & PT-Cushing & DRB & un & un & + & Aneurysm & ESt & NS \\
\hline 7 & $\begin{array}{l}6 \\
(17)\end{array}$ & un & PT-NP & TD & $\mathrm{L}$ & SKC & un & Stenosis & ESa & Ex \\
\hline 8 & $\begin{array}{l}6 \\
(17)\end{array}$ & un & PT-PRL & TR & $\mathrm{L}$ & $\mathrm{BS}$ & un & PA & $\mathrm{EVt}$ & NS \\
\hline 9 & $\begin{array}{l}6 \\
(17)\end{array}$ & un & C & TD & $\mathrm{L}$ & BS & un & Stenosis & $\mathrm{EC}$ & NS \\
\hline 10 & $\begin{array}{l}6 \\
(17)\end{array}$ & un & C & TR & $\mathrm{R}$ & BS & un & un & ICA intact & UEx \\
\hline 11 & $\begin{array}{l}6 \\
(17)\end{array}$ & un & M & DRB & $R$ & $\mathrm{Pac}$ & un & Mild stenosis & ICA intact & NS \\
\hline 12 & $\begin{array}{l}7 \\
(18)\end{array}$ & $31 / \mathrm{M}$ & GCT & DRB & $\mathrm{L}$ & $\mathrm{Pac}$ & + & MCA thrombus & $\mathrm{EC}$ & NS \\
\hline 13 & $\begin{array}{l}8 \\
(19) \\
\end{array}$ & $54 / \mathrm{F}$ & PT-NP & TR & $\mathrm{L}$ & Pac & + & Stenosis & No treatment/surgery & Ex \\
\hline 14 & $\begin{array}{l}8 \\
(19)\end{array}$ & $61 / \mathrm{F}$ & PT-NP & $\mathrm{DI}$ & $\mathrm{R}$ & Un & + & ICA wall defect & $\begin{array}{l}\text { Good collateral } \\
\text { EBO }\end{array}$ & Ex \\
\hline 15 & $\begin{array}{l}8 \\
(19)\end{array}$ & $40 / F$ & PT-Acro & $\mathrm{DI}$ & $\mathrm{L}$ & Un & + & un & $\begin{array}{l}\text { Good collateral } \\
\text { EBO }\end{array}$ & NS \\
\hline 16 & $\begin{array}{l}8 \\
(19) \\
\end{array}$ & $46 / \mathrm{M}$ & PT-PRL & HS & $\mathrm{R}$ & Un & + & PA & ESt & $N S^{a}$ \\
\hline 17 & $\begin{array}{l}9 \\
(20)\end{array}$ & $29 / F$ & PT & un & un & Pac & + & $\begin{array}{l}\text { PA } \\
\text { PCF }\end{array}$ & ICA-MCA bypass & Li/NA \\
\hline 18 & $\begin{array}{l}9 \\
(20)\end{array}$ & $45 / M$ & PT & un & un & $\mathrm{Pac}$ & + & PCF & ICA-MCA bypass & Li/NA \\
\hline 19 & $\begin{array}{l}9 \\
(20)\end{array}$ & $38 / \mathrm{M}$ & RCC & un & un & $\mathrm{Pac}$ & + & PA & ICA-MCA bypass & Li/NA \\
\hline 20 & $\begin{array}{l}9 \\
(20) \\
\end{array}$ & $65 / M$ & C & un & $\mathrm{R}$ & $\mathrm{Pac}$ & + & Stenosis & $\mathrm{EVt}+\mathrm{ICA}-\mathrm{MCA}$ bypass & Li/NA \\
\hline 21 & $\begin{array}{l}10 \\
(21)\end{array}$ & $37 / \mathrm{M}$ & PT & TD & un & $\mathrm{AC}+\mathrm{MP}$ & + & $\mathrm{N}$ & $\mathrm{N}$ & NS \\
\hline 22 & $\begin{array}{l}10 \\
(21)\end{array}$ & $50 / \mathrm{F}$ & C & TR & un & $\mathrm{AC}+\mathrm{MP}$ & + & $\mathrm{N}$ & $\mathrm{N}$ & NS \\
\hline 23 & $\begin{array}{l}10 \\
(21)\end{array}$ & $54 / \mathrm{F}$ & PT & TR & un & $\mathrm{AC}+\mathrm{MP}$ & + & Limited ICA flow & ESt & Li/NA \\
\hline 24 & $\begin{array}{l}10 \\
(21)\end{array}$ & $76 / \mathrm{F}$ & Cra & DRB & un & $\mathrm{AC}+\mathrm{MP}$ & + & $\mathrm{N}$ & $\mathrm{N}$ & NS \\
\hline 25 & $\begin{array}{l}10 \\
(21)\end{array}$ & $40 / F$ & PT & Spo & un & $\mathrm{AC}+\mathrm{MP}$ & + & No ICA flow & Good collateral & NS \\
\hline 26 & & $82 / \mathrm{F}$ & $M$ & DRB & un & $A C+M P$ & + & $\mathrm{N}$ & $\mathrm{N}$ & NS \\
\hline
\end{tabular}


Table 1 (Continued)

\begin{tabular}{|l|l|l|l|l|l|l|l|l|l|l|}
\hline P & S/ Re & A/G & Pathology & Injury & Side & Initial & IA & Finding & ICA status/Repair & $\begin{array}{l}\text { Patient } \\
\text { status }\end{array}$ \\
\hline $\begin{array}{l}10 \\
(21)\end{array}$ & & & & & & & & & \\
\hline $\begin{array}{l}10 \\
(21)\end{array}$ & $58 / \mathrm{F}$ & FD & DRB & un & AC + MP & + & PA & ESt & NS \\
\hline 28 & $\begin{array}{l}10 \\
(21)\end{array}$ & $69 / \mathrm{M}$ & Car & TR & un & AC + MP & + & CD & Observed & Li/NA \\
\hline 29 & $\begin{array}{l}11 \\
(22)\end{array}$ & un & PT & TR & L & Pac & + & $\begin{array}{l}\text { ICA Wall } \\
\text { defect }\end{array}$ & $\begin{array}{l}\text { EBO } \\
\text { TCS }\end{array}$ & Sq $^{\text {c }}$ \\
\hline 30 & $\begin{array}{l}12 \\
(23)\end{array}$ & $67 / F$ & M & DRB & R & Pac & + & $\begin{array}{l}\text { ICA Wall } \\
\text { defect }\end{array}$ & $\begin{array}{l}\text { Good } \\
\text { Collateral } \\
\text { EC }\end{array}$ & NS $^{\text {d }}$ \\
\hline 31 & $\begin{array}{l}13 \\
(24)\end{array}$ & $44 / \mathrm{M}$ & ESS & un & R & un & + & PA & EC & NS \\
\hline 32 & $\begin{array}{l}14 \\
(25)\end{array}$ & $57 / F$ & C & TR & L & Pac & - & PA & un & NS \\
\hline 33 & CR & $44 / F$ & PT-Acro & TR & L & Pac & + & ICA Wall defect & $\begin{array}{l}\text { ICA trapping } \\
\text { operation }\end{array}$ & NS \\
\hline
\end{tabular}

Abbreviations: A, age; Acro, acromegaly; AC, aneurysm clip; BS, bipolar coagulation/sealing-sacrifice; C, chordoma/chondrosarcoma; Car, carcinoma; CD, carotid dissection; CR, current report; Cra, craniopharyngioma; DI, dura incision; DRB, drilling/remove bone; EBO, endovascular balloon occlusion; EC, endovascular coil; ESa, endovascular sacrifice; ESt, endovascular stenting; EVt, endovascular thrombectomy; ESS, endoscopic sinus surgery; Ex, exitus; FD, fibrous dysplasia; G, gender; GCT, giant cell tumor; HS, hemostasis stage; IA, immediate angiogram; ICA, internal carotid artery; L, left, Li, alive; M, meningioma; MC, microcatheter; MCA, middle cerebral artery; MP, muscular patch; N, normal; NA, not applicable; NBCA, acrylic glue mixed with lipiodol; NP, nonfunctional pituitary tumor; NS, no sequelae; P, patient; Pac, packing; PA, pseudoaneurysm; PCF, poor collateral flow; PRL, prolactinoma; PT, pituitary tumor; Re, references; R, right; RCC, Rathke cleft cyst; S, study; Spo, spontaneous; SKC, Sundt-Kees aneurysm clip; Sq, sequelae; TCS, transcranial surgery; TD, tumor dissection/exposure; TR, tumor resection; UEx, unrelated/delayed ex; un, unknown.

1. 11,12 (Cappabianca et al, 2001)

2. 13 (Liu and Di, 2009)

3. 14 (Zada et al, 2010)

4. 15 (Gondim et al, 2011)

5. 16 (Berker et al, 2012)

6. 17 (Gardner et al, 2013)

7. 18 (lacoangeli et al, 2013)

8. 19 (Kalinin et al, 2013)

9. 20 (Rangel-Castilla et al, 2014)

10. 21 (Padhye et al, 2015)

11. 22 (Magro et al, 2016)

12. 23 (Romero et al, 2017)

13. 24 (Dedmon et al, 2014)

14. 25 (Duek et al, 2017)

${ }^{a}$ Without augmentation of focal neurological deficit.

${ }^{\mathrm{b}}$ Because of the packing and hematoma, the patient had visual worsening that required an intracranial approach.

'Visual field and acuity remained severely worsened.

${ }^{d}$ Four months later, the patient received an orbitofrontal craniotomy to remove the tumor.

with prolactinomas, and the lesion type was not provided for 6 patients). The other pathologies were chordoma-chondrosarcomas in five patients, meningiomas in three patients, carcinoma in two patients, and one patient had craniopharyngioma, fibrous dysplasia, Rathke cleft cyst, giant cell tumor, and endoscopic sinus surgery each. In total, cavernous segment injury occurred mostly during tumor resection in nine patients and drilling/remove bone in eight patients; it also occurred during tumor dissection in five patients, dura incision in three patients, and finally during hemostasis stage in one patient. It was reported to occur spontaneously in one patient, whereas no such data was obtained for six patients. The injury was left-sided in 11 patients and rightsided in 9 patients (data unavailable for 13 patients). Packing was the most common initial method to treat the injury (16 patients). An immediate angiogram was performed in all patients except one (no data for one series). Endovascular treatment was the most commonly used treatment method. Most patients had no sequelae (21 cases) and were alive; however, sufficient information on outcomes was lacking in 


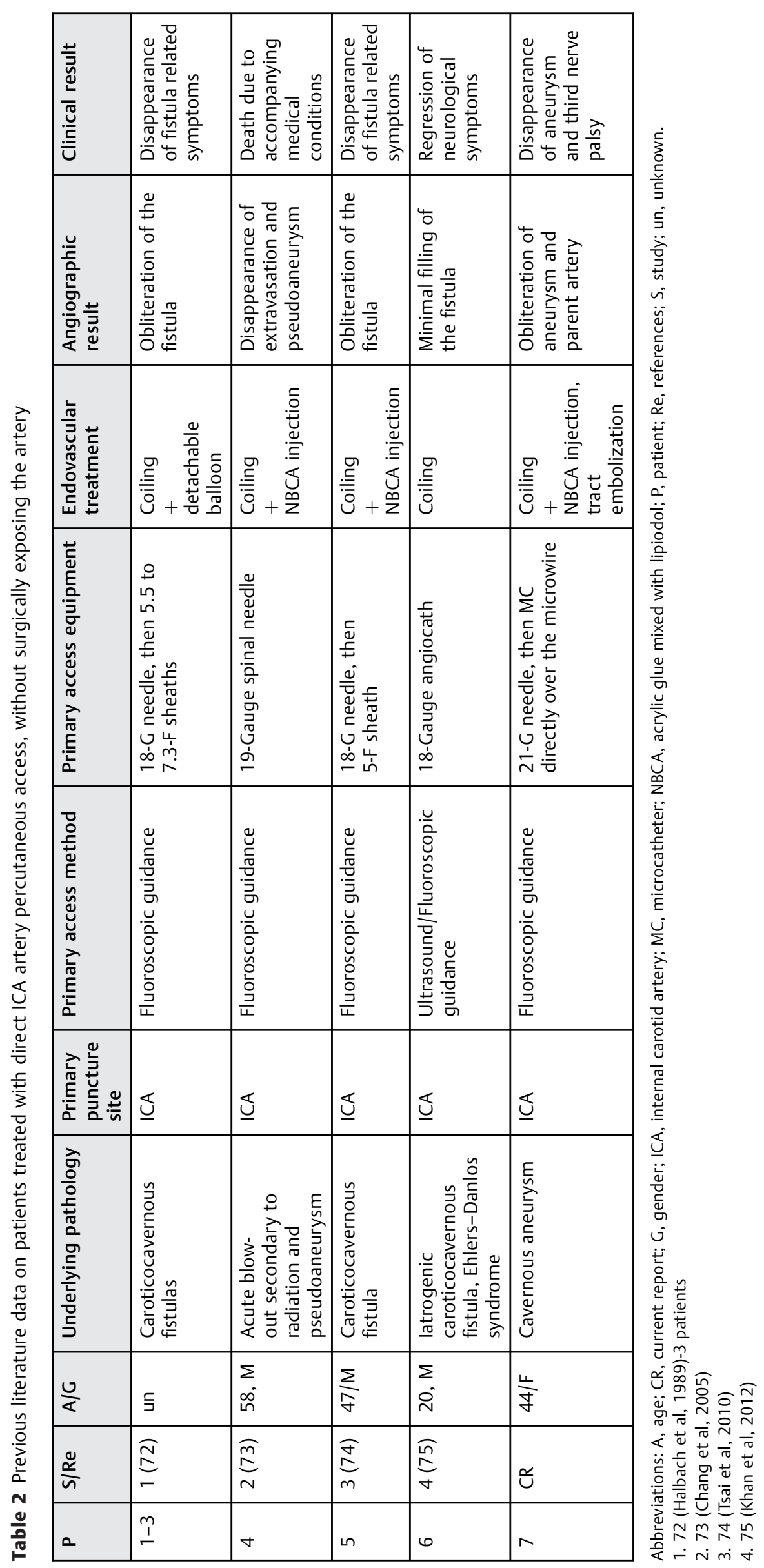


seven patients. One patient had a sequela and another died due to unrelated reasons later. Three deaths were directly related to the procedure.

Although several model studies and surgical simulations have been reported on the management of this complication, vascular injury can be managed with a few methods in the acute setting. ${ }^{53-58}$ In cases of small injury, the opening can be sealed off with the help of a bipolar electrode with or without using the muscle tissue. ${ }^{5,41,59-61}$ However, this may result in pseudoaneurysm formation with unstable seal. ${ }^{62-64}$ Suturing the site of injury is an option; however, it can be hard to perform in EES and generally results in a high-degree stenosis. ${ }^{4}$ Again, clipping the injury site is also an option; however, this can lead to pseudoaneurysm formation, if not stenosis or ischemia. ${ }^{59,60}$ If none of these is possible, the artery should be temporarily wrapped, and endovascular treatment should be considered. ${ }^{8,30,49,65-68}$ Padhye et al described the effects of endoscopic direct clamp closure and muscle patch application in their multicenter study. ${ }^{21}$ Among nine patients with arterial injury during EES (one basilar artery and eight ICA), no deaths occurred, one had pseudoaneurysm with successful endovascular treatment, two had impaired carotid flow, and one with carotid dissection was conservatively managed. Finally, if endovascular options are limited or unavailable, transcranial approaches such as an extracranial-to-intracranial bypass or transcavernous approach can be utilized in arterial or ICA injury due to a transsphenoidal approach. ${ }^{20,69,70}$ In our case, ICA trapping was performed based on the intraoperative angiogram, because proximal arterial control should be first achieved via a cervical incision. Since this remained as our only means to salvage the injury, we suggest that tissues surrounding the carotid sheath should be carefully maintained intraoperatively in widely spread lesions like chordomas.

The largest number of ICA injuries from a single center was described by Gardner et al. ${ }^{17}$ who found seven patients with a $0.3 \%$ incidence. They performed bipolar coagulation/ sealing, with Sundt-Kees aneurysm clip or clip sacrifice, in these patients with further endovascular treatment during follow-up in some patients. A particular endovascular approach was also utilized in our patient during follow-up. Due to the reconstitution of the internal carotid flow via external carotid artery branches above the clipped segment of the carotid artery, vascular access options were limited. The transwillis approach was possible but would endanger both carotid circulations should a problem occur during embolization. Hence, the operator opted to puncture the cervical ICA directly and used the microcatheter alone, (without a sheath, needle, or catheter) to navigate until the dural ring level to perform parent artery occlusion with coils. Since arterial puncture occurred above the neck of the mandible, hemostasis using compression would be impossible. Although the use of arterial closure devices in the cervical approach has been described, ${ }^{71}$ the lack of a safe distal landing zone for the deployment sheath in our case precluded the use of these devices. Consequently, the operator preferred to perform puncture-track embolization using the cyanoacrylate glue. A similar endovascular approach alone for internal carotid access without surgically exposing the carotid artery was previously reported in the literature in four papers to treat a total of five patients with residual carotid cavernous fistulas and one with a history of nasopharyngeal carcinoma and radiotherapy to acute carotid blow-out. ${ }^{72-75}$ Review of these six patients is presented in - Table 2. Among them, Tsai et al could puncture the carotid artery low enough to enable sheath placement and subsequent closure with an arterial closure device, and Halbach et al also used a large sheath and finally embolized the carotid artery with coils. Khan et al used an $18-G$ needle as an access sheath, whereas Chang et al performed the embolization procedure only using a $19-G$ needle. A bare microcatheter technique using merely a microcatheter without an outer sheath or needle has not been reported to directly access the ICA, to our knowledge. This bare microcatheter technique allowed us to make a 1.7-F puncture hole only in the carotid artery, minimizing the risk of a puncture site hematoma. Regardless of this tiny hole, we further secured the access tract-by "tract embolization" with liquid embolic agents, which, again to our knowledge, has not been previously performed for carotid access.

\section{Conclusion}

ICA injury is one of the serious complications that can occur during EES. In our rare case, this EES complication was successfully managed in a unique manner, by reverting to transcranial/transcervical carotid trapping followed by a parent artery sacrifice with direct internal carotid puncture, using a bare microcatheter technique and tract embolization. Both techniques may be lifesaving in case of a devastating carotid injury during EES.

\section{Abbreviations}

A Age

Acro Acromegaly

AC Aneurysm clip

BS Bipolar coagulation/sealing-sacrifice

C Chordoma/chondrosarcoma

Car Carcinoma

CD Carotid Dissection

CR Current report

Cra Craniopharyngioma

DI Dura incision

DRB Drilling/remove bone

EBO Endovascular balloon occlusion

EC Endovascular coil

ESa Endovascular sacrifice

ESt Endovascular stenting

EVt Endovascular thrombectomy

ESS Endoscopic sinus surgery

Ex Exitus

FD Fibrous dysplasia

G Gender

GCT Giant cell tumor

HS Haemostasis stage 
IA Immediate angiogram

ICA Internal carotid artery

L Left

Li Alive

M Meningioma

MC Microcatheter

MCA Middle cerebral artery

MP Muscular patch

N Normal

NA Not applicable

NBCA Acrylic glue mixed with lipiodol

NP Non-functional pituitary tumor

NS No sequelae

$\mathrm{P} \quad$ Patient

Pac Packing

PA Pseudoaneurysm

PCF Poor collateral flow

PRL Prolactinoma

PT Pituitary tumor

Re References

R Right

RCC Rathke cleft cyst

S Study

Spo Spontaneous

SKC Sundt-Kees aneurysm clip

Sq Sequelae

TCS Transcranial surgery

TD Tumor dissection/exposure

TR Tumor resection

UEx Unrelated/delayed ex

un Unknown

Funding

None.

\section{Conflict of Interest}

None declared.

\section{References}

1 Schwartz TH, Fraser JF, Brown S, Tabaee A, Kacker A, Anand VK. Endoscopic cranial base surgery: classification of operative approaches. Neurosurgery 2008;62(05):991-1002, discussion 1002-1005

2 Ciric I, Ragin A, Baumgartner C, Pierce D. Complications of transsphenoidal surgery: results of a national survey, review of the literature, and personal experience. Neurosurgery 1997;40(02): 225-236, discussion 236-237

3 Berker M, Aghayev K, Saatci I, Palaoğlu S, Onerci M. Overview of vascular complications of pituitary surgery with special emphasis on unexpected abnormality. Pituitary 2010;13(02):160-167

4 Solares CA, Ong YK, Carrau RL, et al. Prevention and management of vascular injuries in endoscopic surgery of the sinonasal tract and skull base. Otolaryngol Clin North Am 2010;43(04):817-825

5 Weidenbecher M, Huk WJ, Iro H. Internal carotid artery injury during functional endoscopic sinus surgery and its management. Eur Arch Otorhinolaryngol 2005;262(08):640-645

6 Babgi M, Alsaleh S, Babgi Y, Baeesa S, Ajlan A. Intracranial intradural vascular injury during endoscopic endonasal transsphenoi- dal surgery: a case report and literature review. J Neurol Surg Rep 2020;81(03):e52-e58

7 Kahilogullari G, Meco C, Beton S, et al. Endoscopic transnasal skull base surgery in pediatric patients. J Neurol Surg B Skull Base 2020; 81(05):515-525

8 Kocer N, Kizilkilic O, Albayram S, Adaletli I, Kantarci F, Islak C. Treatment of iatrogenic internal carotid artery laceration and carotid cavernous fistula with endovascular stent-graft placement. AJNR Am J Neuroradiol 2002;23(03):442-446

9 Safaee M, Young JS, El-Sayed IH, Theodosopoulos PV. Management of noncatastrophic internal carotid artery injury in endoscopic skull base surgery. Cureus 2019;11(08):e5537

10 Pham M, Kale A, Marquez Y, et al. Management of carotid artery injury during endoscopic endonasal skull base surgery. J Neurol Surg B Skull Base 2014;75:309-313

11 Cappabianca P, Briganti F, Cavallo LM, de Divitiis E. Pseudoaneurysm of the intracavernous carotid artery following endoscopic endonasal transsphenoidal surgery, treated by endovascular approach. Acta Neurochir (Wien) 2001;143(01):95-96

12 Cappabianca P, Cavallo LM, Colao A, de Divitiis E. Surgical complications associated with the endoscopic endonasal transsphenoidal approach for pituitary adenomas. J Neurosurg 2002;97 (02):293-298

13 Liu HS, Di X. Endoscopic endonasal surgery for biopsy of cavernous sinus lesions. Minim Invasive Neurosurg 2009;52 (02):69-73

14 Zada G, Cavallo LM, Esposito F, et al. Transsphenoidal surgery in patients with acromegaly: operative strategies for overcoming technically challenging anatomical variations. Neurosurg Focus 2010;29(04):E8

15 Gondim JA, Almeida JPC, Albuquerque LA, et al. Endoscopic endonasal approach for pituitary adenoma: surgical complications in 301 patients. Pituitary 2011;14(02):174-183

16 Berker M, Hazer DB, Yücel T, et al. Complications of endoscopic surgery of the pituitary adenomas: analysis of 570 patients and review of the literature. Pituitary 2012;15(03):288-300

17 Gardner PA, Tormenti MJ, Pant H, Fernandez-Miranda JC, Snyderman $\mathrm{CH}$, Horowitz MB. Carotid artery injury during endoscopic endonasal skull base surgery: incidence and outcomes. Neurosurgery 2013;73(2, Suppl Operative):ons261-ons269, discussion ons269-ons 270

18 Iacoangeli M, Di Rienzo A, Re M, et al. Endoscopic endonasal approach for the treatment of a large clival giant cell tumor complicated by an intraoperative internal carotid artery rupture. Cancer Manag Res 2013;5:21-24

19 Kalinin PL, Sharipov OI, Shkarubo AN, et al. [Damage to the cavernous segment of internal carotid artery in transsphenoidal endoscopic removal of pituitary adenomas (report of 4 cases)]. Vopr Neirokhir 2013;77(06):28-37, discussion 38

20 Rangel-Castilla L, McDougall CG, Spetzler RF, Nakaji P. Urgent cerebral revascularization bypass surgery for iatrogenic skull base internal carotid artery injury. Neurosurgery 2014;10 (Suppl 4):640-647, discussion 647-648

21 Padhye V, Valentine R, Sacks R, et al. Coping with catastrophe: the value of endoscopic vascular injury training. Int Forum Allergy Rhinol 2015;5(03):247-252

22 Magro E, Graillon T, Lassave J, et al. Complications related to the endoscopic endonasal transsphenoidal approach for nonfunctioning pituitary macroadenomas in 300 consecutive patients. World Neurosurg 2016;89:442-453

23 Romero ADCB, Lal Gangadharan J, Bander ED, Gobin YP, Anand VK, Schwartz TH. Managing arterial injury in endoscopic skull base surgery: case series and review of the literature. Oper Neurosurg (Hagerstown) 2017;13(01):138-149

24 Dedmon M, Meier J, Chambers K, et al. Delayed endovascular coil extrusation following internal carotid artery embolization. J Neurol Surg Rep 2014;75(02):e255-e258 
25 Duek I, Sviri GE, Amit M, Gil Z. Endoscopic endonasal repair of internal carotid artery injury during endoscopic endonasal surgery. J Neurol Surg Rep 2017;78(04):e125-e128

26 Snyderman $\mathrm{CH}$, Pant H, Carrau RL, Prevedello D, Gardner P, Kassam $A B$. What are the limits of endoscopic sinus surgery?: the expanded endonasal approach to the skull base Keio J Med 2009;58(03):152-160

27 Dehdashti AR, Ganna A, Witterick I, Gentili F. Expanded endoscopic endonasal approach for anterior cranial base and suprasellar lesions: indications and limitations. Neurosurgery 2009;64 (04):677-687, discussion 687-689

28 Zanation AM, Carrau RL, Snyderman CH, et al. Nasoseptal flap reconstruction of high flow intraoperative cerebral spinal fluid leaks during endoscopic skull base surgery. Am J Rhinol Allergy 2009;23(05):518-521

29 Cavallo LM, Briganti F, Cappabianca P, et al. Hemorrhagic vascular complications of endoscopic transsphenoidal surgery. Minim Invasive Neurosurg 2004;47(03):145-150

30 Valentine R, Wormald PJ. Carotid artery injury after endonasal surgery. Otolaryngol Clin North Am 2011;44(05):1059-1079

31 Laws ER Jr. Vascular complications of transsphenoidal surgery. Pituitary 1999;2(02):163-170

32 Alahmadi H, Dehdashti AR, Gentili F. Endoscopic endonasal surgery in recurrent and residual pituitary adenomas after microscopic resection. World Neurosurg 2012;77(34):540-547

33 Pasquini E, Zoli M, Frank G. Endoscopic endonasal surgery: new perspectives in recurrent and residual pituitary adenomas. World Neurosurg 2012;77(3-4):457-458

34 Halvorsen H, Ramm-Pettersen J, Josefsen R, et al. Surgical complications after transsphenoidal microscopic and endoscopic surgery for pituitary adenoma: a consecutive series of 506 procedures. Acta Neurochir (Wien) 2014;156(03):441-449

35 Frank G, Pasquini E, Farneti G, et al. The endoscopic versus the traditional approach in pituitary surgery. Neuroendocrinology 2006;83(3-4):240-248

36 Ammirati M, Wei L, Ciric I. Short-term outcome of endoscopic versus microscopic pituitary adenoma surgery: a systematic review and meta-analysis. J Neurol Neurosurg Psychiatry 2013; $84(08): 843-849$

37 Fang X, Di G, Zhou G, et al. The anatomy of the parapharyngeal segment of the internal carotid artery for endoscopic endonasal approach. Neurosurg Rev 2019; ‘..;. Doi: 10.1007/s10143-01901176-3

38 Dal Secchi MM, Dolci RLL, Teixeira R, Lazarini PR. An analysis of anatomic variations of the sphenoid sinüs and its relationship to the internal carotid artery. Int Arch Otorhinolaryngol 2018;22 (02):161-166

39 Truong HQ, Najera E, Zanabria-Ortiz R, et al. Surgical anatomy of the superior hypophyseal artery and its relevance for endoscopic endonasal surgery. J Neurosurg 2018;131(01):154-162

40 Skandalakis GP, Koutsarnakis C, Pantazis N, et al. The caroticoclinoid bar: a systematic review and meta-analysis of its prevalence and potential implications in cerebrovascular and skull base surgery. World Neurosurg 2019;124:267-276

41 Rowan NR, Turner MT, Valappil B, et al. Injury of the carotid artery during endoscopic endonasal surgery: surveys of skull base surgeons. J Neurol Surg B Skull Base 2018;79(03): 302-308

42 AlQahtani A, London NR Jr, Castelnuovo P, et al. Assessment of factors associated with internal carotid injury in expanded endoscopic endonasal skull base surgery. JAMA Otolaryngol Head Neck Surg 2020;146(04):364-372

43 Dziedzic T, Koczyk K, Gotlib T, Kunert P, Maj E, Marchel A. Sphenoid sinus septations and their interconnections with parasphenoidal internal carotid artery protuberance: radioanatomical study with literature review. Wideochir Inne Tech Malo Inwazyjne 2020;15(01):227-233
44 Erdogan U, Turhal G, Kaya I, et al. Cavernous sinus and parasellar region: An endoscopic endonasal anatomic cadaver dissection. J Craniofac Surg 2018;29(07):e667-e670

45 Feng Y, Zhao JW, Liu M, et al. Internal carotid artery in the operative plane of endoscopic endonasal transsphenoidal surgery. J Craniofac Surg 2012;23(03):909-912

46 Zhang Y, Tian Y, Song J, Li Y, Li W. Internal carotid artery in endoscopic endonasal transsphenoidal surgery. J Craniofac Surg 2012;23(06):1866-1869

47 Perry A, Graffeo CS, Meyer J, et al. Beyond the learning curve: comparison of microscopic and endoscopic incidences of internal carotid artery injury in a series of highly experienced operators. World Neurosurg 2019;131:e128-e135

48 Valentine R, Wormald PJ. Controlling the surgical field during a large endoscopic vascular injury. Laryngoscope 2011;121(03): 562-566

49 Koitschev A, Simon C, Löwenheim H, Naegele T, Ernemann U. Management and outcome after internal carotid artery laceration during surgery of the paranasal sinuses. Acta Otolaryngol 2006; 126(07):730-738

50 Fastenberg JH, Garzon-Muvdi T, Hsue V, et al. Adenosine-induced transient hypotension for carotid artery injury during endoscopic skull-base surgery: case report and review of the literature. Int Forum Allergy Rhinol 2019;9(09):1023-1029

51 Zhang HK, Ma N, Sun XC, Wang DH. Endoscopic repair of the injured internal carotid artery utilizing oxidized regenerated cellulose and a free fascia lata graft. J Craniofac Surg 2016;27 (04):1021-1024

52 Chin OY, Ghosh R, Fang CH, Baredes S, Liu JK, Eloy JA. Internal carotid artery injury in endoscopic endonasal surgery: a systematic review. Laryngoscope 2016;126(03):582-590

53 Valentine R, Wormald PJ. A vascular catastrophe during endonasal surgery: an endoscopic sheep model. Skull Base 2011;21(02): 109-114

54 Maza G, VanKoevering KK, Yanez-Siller JC, et al. Surgical simulation of a catastrophic internal carotid artery injury: a lasersintered model. Int Forum Allergy Rhinol 2019;9(01):53-59

55 Muto J, Carrau RL, Oyama K, Otto BA, Prevedello DM. Training model for control of an internal carotid artery injury during transsphenoidal surgery. Laryngoscope 2017;127(01):38-43

56 Pacca P, Jhawar SS, Seclen DV, et al. 'Live Cadaver' model for internal carotid artery injury simulation in endoscopic endonasal skull base surgery. Oper Neurosurg (Hagerstown) 2017;13(06): 732-738

57 Shen J, Hur K, Zhang Z, et al. Objective validation of perfusionbased human cadaveric simulation training model for management of internal carotid artery injury in endoscopic endonasal sinus and skull base surgery. Oper Neurosurg (Hagerstown) 2018; 15(02):231-238

58 Dusick JR, Esposito F, Malkasian D, Kelly DF. Avoidance of carotid artery injuries in transsphenoidal surgery with the Doppler probe and micro-hook blades. Neurosurgery 2007;60(4, Suppl 2):322-328, discussion 328-329

59 Raymond J, Hardy J, Czepko R, Roy D. Arterial injuries in transsphenoidal surgery for pituitary adenoma; the role of angiography and endovascular treatment. AJNR Am J Neuroradiol 1997;18 (04):655-665

60 Ahuja A, Guterman LR, Hopkins LN. Carotid cavernous fistula and false aneurysm of the cavernous carotid artery: complications of transsphenoidal surgery. Neurosurgery 1992;31(04):774-778, discussion 778-779

61 Wang WH, Lieber S, Lan MY, et al. Nasopharyngeal muscle patch for the management of internal carotid artery injury in endoscopic endonasal surgery. J Neurosurg 2019;18:1-6

62 Valentine R, Boase S, Jervis-Bardy J, Dones Cabral JD, Robinson S, Wormald PJ. The efficacy of hemostatic techniques in the sheep model of carotid artery injury. Int Forum Allergy Rhinol 2011;1 (02):118-122 
63 Padhye V, Valentine R, Paramasivan S, et al. Early and late complications of endoscopic hemostatic techniques following different carotid artery injury characteristics. Int Forum Allergy Rhinol 2014;4(08):651-657

64 Karadag A, Kinali B, Ugur O, Oran I, Middlebrooks EH, Senoglu M. A case of pseudoaneurysm of the internal carotid artery following endoscopic endonasal pituitary surgery: endovascular treatment with flow-diverting stent implantation. Acta Med (Hradec Kralove) 2017;60(02):89-92

65 Biswas D, Daudia A, Jones NS, McConachie NS. Profuse epistaxis following sphenoid surgery: a ruptured carotid artery pseudoaneurysm and its management. J Laryngol Otol 2009;123(06):692-694

66 Cobb MI, Nimjee S, Gonzalez LF, Jang DW, Zomorodi A. Direct repair of iatrogenic internal carotid artery injury during endoscopic endonasal approach surgery with temporary endovascular balloon-assisted occlusion: technical case report. Neurosurgery 2015;11(Suppl 3):E483-E486, discussion E486-E487

67 Zhang Y, Tian Z, Li C, et al. A modified endovascular treatment protocol for iatrogenic internal carotid artery injuries following endoscopic endonasal surgery. J Neurosurg 2019;132(02): 343-350

68 Sylvester PT, Moran CJ, Derdeyn CP, et al. Endovascular management of internal carotid artery injuries secondary to endonasal surgery: case series and review of the literature. J Neurosurg 2016;125(05):1256-1276
69 Dolenc VV, Lipovsek M, Slokan S. Traumatic aneurysm and carotid-cavernous fistula following transsphenoidal approach to a pituitary adenoma: treatment by transcranial operation. $\mathrm{Br} \mathrm{J}$ Neurosurg 1999;13(02):185-188

70 Oskouian RJ, Kelly DF, Laws ERJ Jr. Vascular injury and transsphenoidal surgery. Front Horm Res 2006;34:256-278

71 Orlov K, Arat A, Osiev A, et al. Transvenous treatment of carotid aneurysms through transseptal access. World Neurosurg 2019: S1878-8750(19)30086-5. Doi: 10.1016/j.wneu.2018.12.207

72 Halbach VV, Higashida RT, Hieshima GB, Hardin CW. Direct puncture of the proximally occluded internal carotid artery for treatment of carotid cavernous fistulas. AJNR Am J Neuroradiol 1989;10(01):151-154

73 Chang FC, Lirng JF, Luo CB, Teng MM, Guo WY, Chang CY. Carotid blowout treated by direct percutaneous puncture of internal carotid artery with temporary balloon occlusion. Interv Neuroradiol 2005;11(04):349-354

74 Tsai YH, Weng HH, Chen YL, Wu YM, Wong HF. Treatment of recurrent carotid cavernous fistula by direct puncture of a previously trapped internal carotid artery. J Vasc Interv Radiol 2010;21(05):738-740

75 Khan A, Chaudhary N, Pandey AS, Gemmete JJ. Direct puncture of the highest cervical segment of the internal carotid artery for treatment of an iatrogenic carotid cavernous fistula in a patient with Ehlers-Danlos syndrome. J Neurointerv Surg 2012;4(05):e29 